\title{
Ebstein's anomaly repair in infant and adult: Report of two cases
}

\author{
Kabir $\mathrm{J}^{1}$, Rima $\mathrm{R}^{2}$, Khatoon $\mathrm{S}^{3}$, Hassan $\mathrm{R}^{4}$, Hossain $\mathrm{MZ}^{5}$
}

\begin{abstract}
Ebstein's anomaly (EA) is a rare but fascinating congenital heart disorder accounting for $<1 \%$ of all congenital heart defects. It is a complex congenital anomaly with a broad pathologic-anatomical and clinical spectrum and no two patients are alike. Moderate to severe Ebstein's malformation remains a surgical challenge. We report our institutional experience with the surgical management of Ebstein's anomaly in a severely symptomatic four months old infant and a twenty year old grown up adult. The young infant with Ebstein's anomaly had severe tricuspid valve dysplasia, cyanosis, and gross cardiomegaly, hepatomegaly. Echocardiography severity score was 1.1 in infant (grade 3/4). Repair consisted of tricuspid valve repair, reduction annuloplasty, partial closure of atrial septal defect, and correction of all associated cardiac defects (PDA ligation).Adult Ebstein's anomaly patient underwent One and half ventricle repair which includes De-Vega repair of tricuspid valve, plication of atrialized RV, closure of ASD and a bidirectional Glenn shunt as part of the repair. The postoperative course was uneventful in adult patient except mild RV diastolic dysfunction. The infant required prolonged mechanical ventilatory support. She also developed lungs collapse-consolidation following extubation and septicaemia. At 2 years follow-up both patients showed improved exercise tolerance, infant showed significant weight gain. Echocardiographic studies reveal satisfactory monocusp valve function in both patients, with mild non- coaptation of the anterior leaflet and the septal structures with mild tricuspid valve regurgitation. Ebstein's repair has a good functional and hemodynamic outcome in infant and adult patients. One and one-half ventricular repair can be performed with an acceptable risk in adult and a biventricular repair is feasible and safe in a symptomatic infant.
\end{abstract}

Key word: Ebstein's anomaly, ASD, Glenn Shunt.

\section{Introduction}

Ebstein's anomaly (EA) is a rare congenital heart disorder which occurs in about 1-5 per 200.000 live births, accounting for $<1 \%$ of all congenital heart disease $\mathrm{e}^{1-3}$. Although the morphology was described by Wilhelm Ebstein $^{4}$ in 1866, the clinical entity known as Ebstein's anomaly (EA) was first documented by Helen Taussig ${ }^{5}$ in 1950. The primary underlying abnormality is failure of adequate delamination of the tricuspid valve (TV) leaflets from the endocardium of the right ventricle. This result is varying degrees of displacement of the septal and posterior leaflets into the cavity of the dysfunctional right ventricle $^{6-9}$ and results in progressive tricuspid valve regurgitation, congestive cardiac failure at infancy and arrhythmias in adolescence and early adulthood ${ }^{10-14}$. There are heterogeneous genetic factors in EA. Most cases are sporadic; familial EA is rare. Maternal lithium therapy may in rare cases lead to Ebstein's anomaly of the offspring $^{15}$. Other environmental factors such as viral infections are in rare cases of Ebstein's anomaly. This anomaly is currently most easily diagnosed by echocardiography. In the past, diagnosis was established most commonly at autopsy. The spectrum of variation is wide from one patient to the other and no two patients are alike $^{16}$. Management of EA patients is complex. Valve repairs are feasible if the anterior leaflet is mobile and not too deficient at least $50 \%$ of normal size. Repairs may be done with or without internal plication of the atrialized right ventricle. A key point in the surgical results appears to be the right ventricular contractility ${ }^{17}$. However, when EA becomes clinically evident in the neonatal period the condition is often fatal ${ }^{18-21}$. In the severely symptomatic neonate EA seems to be associated with more complex morphology and pathophysiology ${ }^{18,19,22}$. and continues to have a dismal prognosis despite various surgical interventions both conservative and aggressive ${ }^{18,22}$. In this report it presents the institutional experience with the surgical management of Ebstein's anomaly in severely symptomatic four months old infant and a twenty year old grown up adult.

1. Dr. Jahangir Kabir, Chief Cardiac Surgeon \& Director, Cardiac Centre United Hospital Limited, Dhaka

2. Dr. Rezoana Rima, Specialist, Paediatric Cardiology, United Hospital Limited, Dhaka

3. Prof. Soofia Khatoon, Professor \& Head, Department of Pediatrics, Shaheed Suhrawardy Medical College, Dhaka

4. Dr. Rezaul Hassan, Junior. Consultant Cardiac Surgery-United Hospital Limited, Dhaka

5. Dr. Md Zakir Hossain, Specialist Cardiac Surgery, United Hospital Limited, Dhaka

\section{Correspondence}

Dr. Rezoana Rima, Specialist Paediatric Cardiology, United Hospital Limited, Plot 15,Road 71, Gulshan, Dhaka-1212; Mobile No. 01713257521;

E-mail: rezoanabd@yahoo.com 


\section{Case 1}

A four months old infant, second issue bom to a nonconsanguinous parents, presented with dyspnea and tachvpnea noticed since one month of age which is increased in severity for last one month, excessive sweating, interrupted feeding, failure to thrive. Her heart disease was suspected antenatally by ultrasonography scan four days before delivery. Mother has got $\mathrm{H} / \mathrm{O}$ taking omeprazole throughout pregnancy. The baby was delivered by LUCS at term. Her birth weight was $2.5 \mathrm{~kg}$. She was cyanosed at birth and managed at NICU with oxygen and intravenous fluid and medicines. Since then she was getting digoxin, frusemide, captopril at optimum dosages without any improvement. On examination the baby was mildly pale, dyspneic, and tachypneic having subcostal and intercostal chest retraction. She was weighing $3.8 \mathrm{~kg}$, her length was $58 \mathrm{~cm}$, OFC was $37.2 \mathrm{~cm}$. Pulse oximetry showed $\mathrm{O}_{2}$ saturation $85 \%$ in all four limbs. Her respiratory rate was $44 /$ minute, heart rate was 160 beat /minutes, and blood pressure was $80 / 43 \mathrm{~mm}$ of $\mathrm{Hg}$. Wide fixed second heart sound and multiple added heart sounds, systolic murmur on left sternal border were found on chest auscultation. Mild rhonchi was present on both lung fields. Liver was $3 \mathrm{~cm}$ enlarged from right costal margin along midclavicular line. Chest $\mathrm{X}$ Ray was done which showed cardiomegaly (CTR: 0.8), oligaemic lung field. ECG showed right ventricular hypertrophy and complete RBBB. Preoperative echocardiogram revealed anterior leaflet of tricuspid valve was redundant, sail like, tethered and has restricted movement; Septal and posterior leaflets were dysplastic and displaced apically, dilated tricuspid valve annulus (Z-score : +3.5 ), hugely dilated RA; moderate to severe tricuspid regurgitation and moderate pulmonary hypertension. Moderate size ostium secundum ASD shunting Rt - Lt, small size PDA shunting bi-directional and mild juxtaductal narrowing was also present. The Great Ormond Street Ebstein (GOSE) echocardiogram score ${ }^{11,20}$ was 1.1 (grade 3 ).

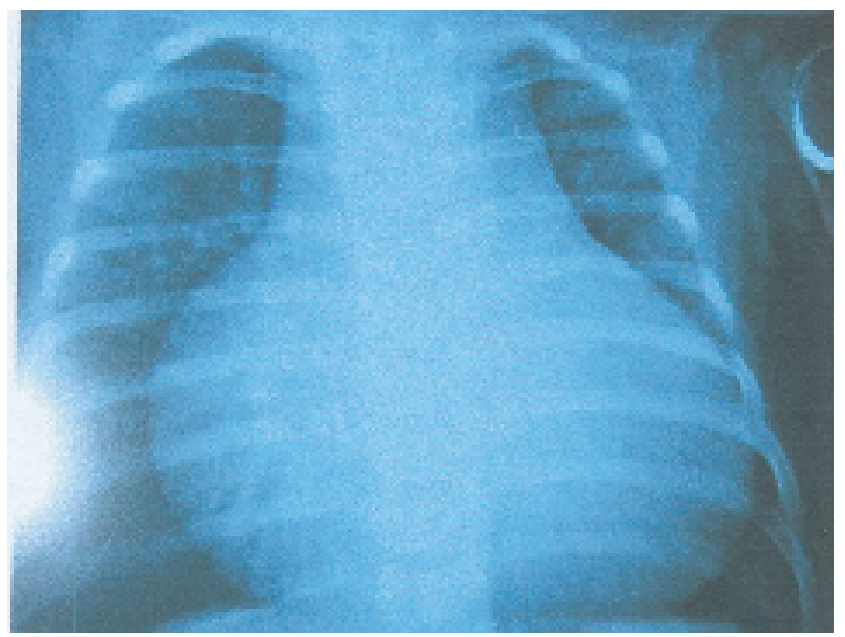

Figure 1: Cardiomegaly at preoperative chest X-ray of Infant
On March 1, 2009, she underwent biventricular repair of Ebstein's anomaly and PDA ligation. The anterior leaflet was large and had tethered at four points, no fenestration in it, and both the septal and posterior leaflets were displaced well into the right ventricle and were dysplastic. The tricuspid annulus was reduced (reduction annuloplasty), construction of a competent monoleaflet tricuspid valve using the modified Danielson technique of placing a pledgetted suture at the anteroposterior commissure and bringing this down to the coronary sinus thus creating a "double orifice" valve, the inferior (lateral) orifice containing the atrialized right ventricle, which may then be closed by plicating it vertically.

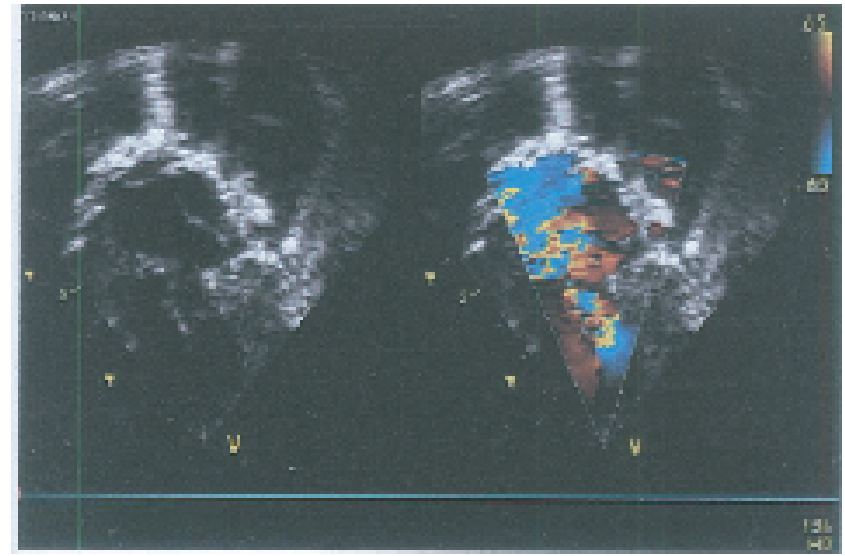

Figure 2: Preoperative Echocardiography of infant with severe tricuspid regurgitation

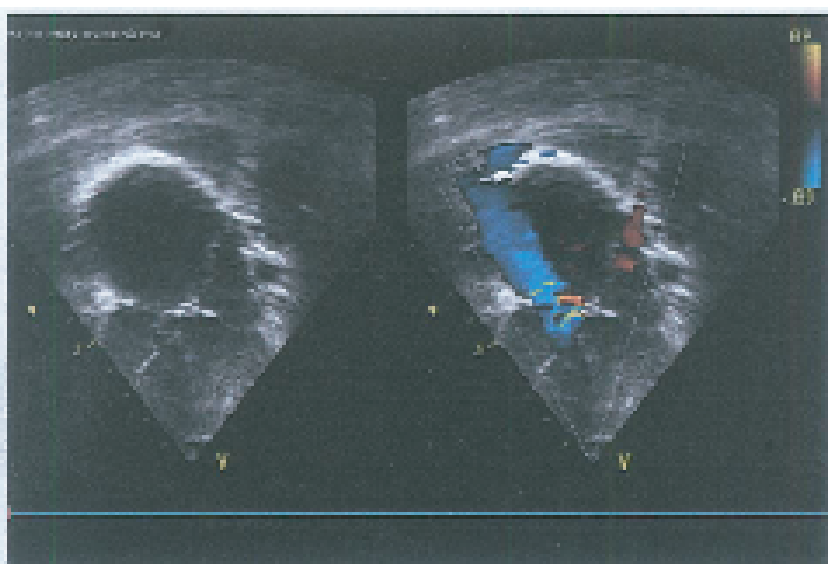

Figure 3: Postoperative Echocardiography of infant with mild tricuspid regurgitation

The ASD was subtotally closed. Cardiopulmonary bypass time was 90 minutes and aortic cross clamp time was 47 minutes. She was maintained on $0.5 \mathrm{meg} / \mathrm{kg} / \mathrm{milrinone}$ for 48 hours, and developed junctional ectopic tachycardia during early postoperative period which was managed conservatively. The postoperative course was complicated by feeding intolerance, septicemia, collapse consolidation of right lung and the patient was extubated on postoperative day 10 , and discharged on postoperative day 
60. The patient is currently 2 years 3 months old and is fully active without restrictions, thriving well, could walk alone, and speak few words. She is in sinus rhythm and takes no medications. Recent echocardiogram showed mild non-coaptation between anterior and septal tricuspid leaflet with mild to moderate tricuspid regurgitation and good biventricular function.

\section{Case 2}

Twenty years old male presented with exercise intolerance, dyspnea on exertion (NYHA class II). palpitation on and off for last 6-7 years. He was taking atenolol for palpitation with no improvement. General physical examination was unremarkable except wide fixed second heart sound and multiple added heart sounds, systolic murmur on left sternal border were found on chest auscultation. ECG showed right ventricular hypertrophy and complete RBBB. Preoperative echocardiogram revealed that anterior leaflet is redundant elongated, sail like \& tethered at multiple points to RV lateral wall, apex till IVS with restricted movement; Thickened dysplastic septal leaflet displaced downwards to $33 \mathrm{~mm}$; Post leaflet rudimentary. Anterior leaflet is coapted to septal leaflet near its midpoint forming three chambers in RV cavity. Moderate low pressure in TR. Dilated true TV annulus ( $\mathrm{Z}$ score: +7.7$)$. Two small secundum ASD is shunting bidirectionally. The patient underwent one and half ventricle repair which includes Devega repair of tricuspid valve, plication of atrialized RV, closure of ASD, right bidirectional Glenn shunt (connection of SVC to RPA)on 20th March 2009. Cardiopulmonary bypass time was 340 minutes and aortic cross clamp time was 70 minutes. He was maintained on $0.5 \mathrm{meg} / \mathrm{kg} / \mathrm{milrinone}$ for 75 hours, 0.01 adrenalin for 48 hours. He was extubated on 3rd POD, developed low cardiac output for 1 st few days due to RV dysfunction and pleural effusion requiring drainage for 10 days. At 18 months follow up his well being and exercise tolerance improved, no palpitation. His recent echocardiogram showed well functioning Glenn shunt, mild low pressure TR, mildly dilated RA and RV, mild RV diastolic dysfunction.

\section{Discussion}

Ebstein's anomaly is a rare congenital heart defect reported to occur in $0.2 \%$ of live births ${ }^{23}$. Most children clinically presenting with EA have signs and symptoms of progressive right heart failure, whereas adults usually present with progressive cyanosis, decreasing exercise tolerance, or arrhythmias $7,10,20,21,24,25,26$. The four months old infant presented with severe right heart failure which could not be managed medically and the adult patient present with exercise intolerance and palpitation. In both instances progressive symptoms warrant surgical intervention. In contradistinction, there is currently no consensus about which neonates with EA would benefit from early surgical intervention. The available data suggest that about $20 \%$ to $40 \%$ of all neonates diagnosed with EA will not survive 1 month, and less than $50 \%$ will survive to 5 years of age $^{14,18,27,28,29}$. The prognosis for symptomatic neonates is almost uniformly fatal in severe cases ${ }^{14,18,28}$. Some mildly symptomatic neonates may, however, be tided over with aggressive intensive care only to succumb in early childhood $^{24,30,31}$. Most, however, will die during the neonatal period. Therefore, the dilemma is to identify which neonates need urgent surgical intervention during the neonatal period.

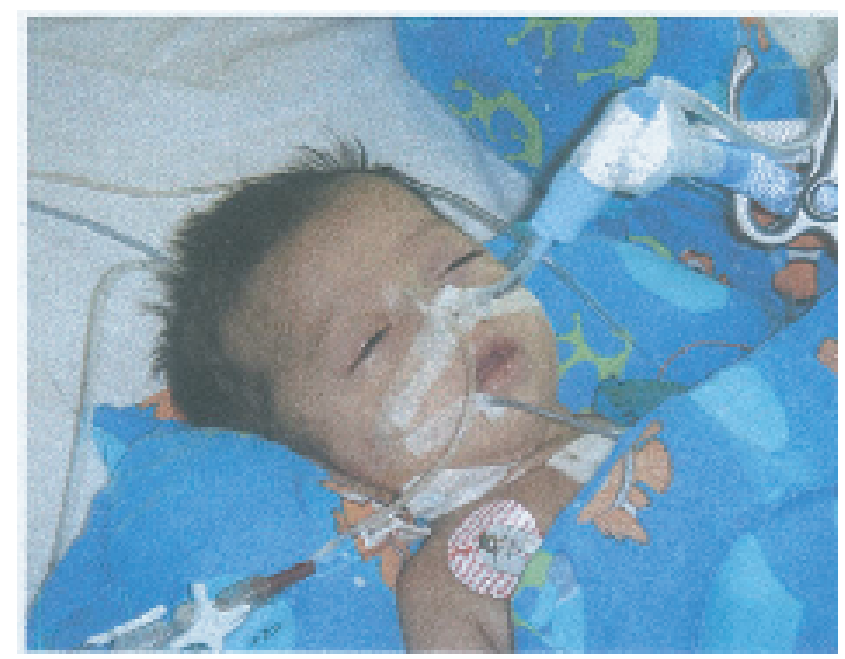

Figure 4: Infant at the age of 4 months at CICU after surgery

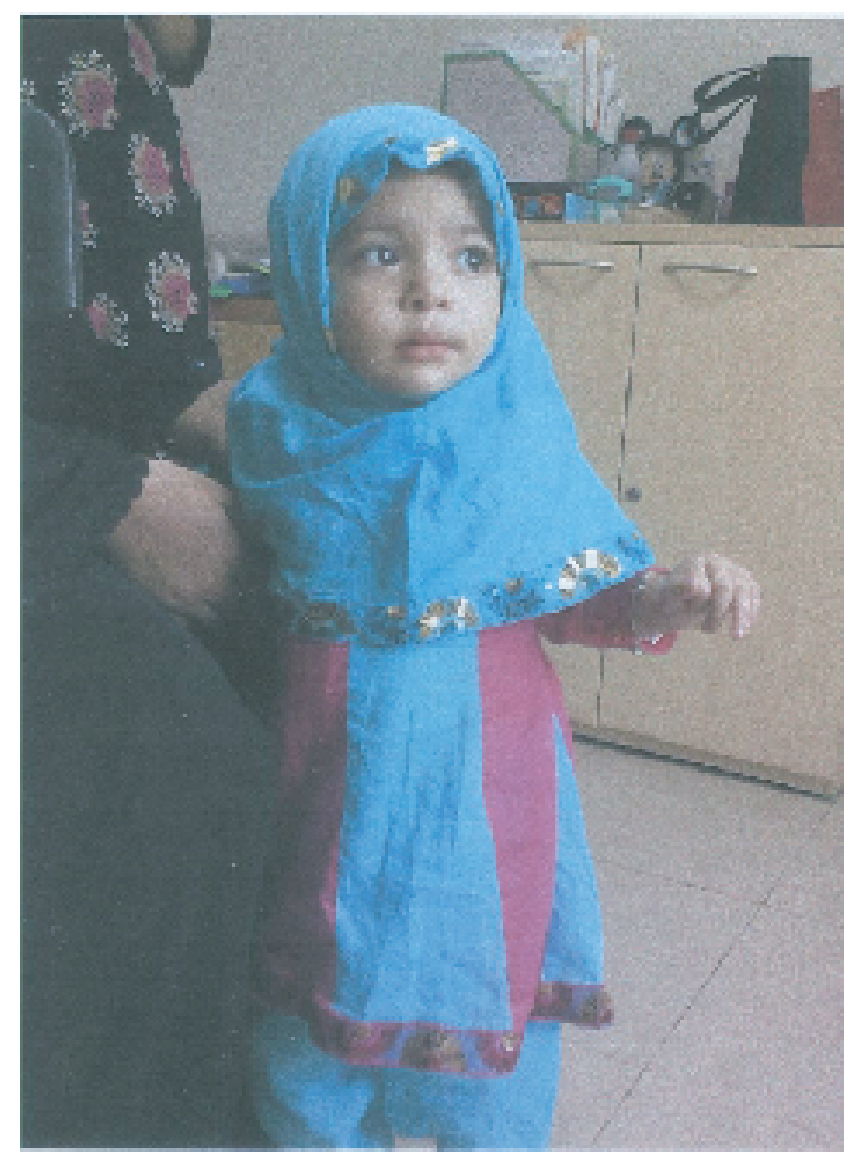

Figure 5: After 1 year of age at follow up 
On the basis of the GOSE score (grade 3), cardiothoracic ratio $(0.85)$, presence of cyanosis, the infant that has been operated would not have survived the neonatal period without operation. The techniques that have been used are directed at creating a largely competent tricuspid valve, obliterating the aneurismal dyskinetic atrialized portion of the right ventricle, maintaining left ventricular output in the presence of a compromised right heart by ensuring that a small ASD is present, and ensuring adequate prograde pulmonary blood flow without overloading the functional right ventricle are well documented in the literature ${ }^{32}$. Adding a bi-directional cavopulmonary shunt to the intracardiac repair of Ebstein's anomaly has decreased the work index of the compromised right ventricle and subsequently prevents postoperative ventricular dilatation. The bi-directional cavopulmonary shunt diverts between 30 and $40 \%$ of the systemic venous return from the right ventricle. The wall stress and work index, even if not measured, is proportional to the decrease of the preload. A bi-directional cavopulmonary shunt was added in adult patient in order to decrease the preload and to avoid acute dilatation of an akinetic right ventricle, recurrent TV insufficiency due to dilatation of the right ventricle ${ }^{33}$. Currently the younger patient is above 2 years old and lead fully active live without medications. Both the patients are in sinus rhythm without evidence of pre-excitation and both has mild residual tricuspid valve regurgitation. It is acknowledged that the younger patient had large anterior leaflets making the tricuspid valve repair easier, but the techniques are adaptable even to situations where the leaflet is tethered to the free wall of the right ventricle.

\section{Conclusion}

Biventricular repair of EA present in the severely symptomatic infant is feasible and the repair appears to be durable Adding a bi-directional cavopulmonary shunt to the intracardiac repair of Ebstein's anomaly has decreased the work index of the compromised right ventricle and subsequently prevent postoperative ventricular dilatation in adult with a potentially compromised right ventricle. Timing of surgical intervention is critical and the operative technique and perioperative management needs to be carefully tailored to the individual needs of the patient.

\section{References}

1. Perloff JK. The clinical recognition of congenital heart disease.2003; Saunders W B CO:194-215

2. Brickner ME, Hillis LD, Lange RA. Congenital heart disease in adults. Second of two parts. N Engl J Med 2000;342:334-42

3. Dearani JA, Danielson GK. Congenital Heart Surgery Nomenclature and Database Project: Ebstein's anomaly and tricuspid valve disease. Ann Thorac Surg 2000;69(4): 106-17

4. Ebstein W. Ueber einen sehr seltenen Fall von Insufficienz der Valvula tricuspidalis, bedingt durch eine angeborene hochgradige Missbildung derselben. Arch Anat Physiol Wissenschafliche Med 1866;33:238-54

5. Engle MA, Payne TPB, Bruins C, Taussig HB.Ebstein's anomaly of the tricuspid valve.Report of three cases and analysis of clinical syndrome.Circulation 1950; 1:1246-60
6. Schreiber C, Cook A, Ho SY, Augustin N, Anderson RH. Morphologic spectrum of Ebstein's malformation: revisitation relative to surgical repair. J Thorac Cardiovasc Surg 1999; 117:148-55

7. Rusconi PG, Zuberbuhler JR, Anderson RH, Rigby ML. Morphologicechocardiographic correlates of Ebstein's malformation. Eur Heart J 1991; 12:784-90

8. Hardy KL May LA, Webster CA, Kimball KG. Ebstein's anomaly: a functional concept and successful definitive repair. J Thorac Cardiovasc Surg 1964;48:927-40

9. Madiwale CV, Deshpande JR, Kinare SG. Ebstein's anomaly-an autopsy study of 28 cases. J Postgrad Med 1997;43:8-11

10. Danielson GK, Driscoll DJ, Mair DD, Wames CA, Oliver WC, Jr. Operative treatment of Ebstein's anomaly. J Thorac Cardiovasc Surg 1992; 104:1195-202

11. Chauvaud S. Ebstein's malformation. Surgical treatment and results. Thorac Cardiovasc Surg 2000; 48:220-3

12. Carpentier A, Chauvaud S, Mace L, et al. A new reconstructive operation for Ebstein's anomaly of the tricuspid valve. J Thorac Cardiovasc Surg 1988; 96:92-101

13. Giuliani ER, Fuster V, Brandenburg RO, Mair DD. Ebstein's anomaly: the clinical features and natural history of Ebstein's anomaly of the tricuspid valve. Mayo Clin Proc 1979; 54:163-73

14. Augustin N, Schmidt-Habelmann P, Wottke M, Meisner H. Sebening F. Results after surgical repair of Ebstein's anomaly. Ann Thorac Surg 1997;63:1650-6

15. Cohen LS, Friedman JM, Jefferson JW, Johnson EM, Weiner ML. A reevaluation of risk of in utero exposure to lithium. JAMA 1994; 271:146-50 16. Zuberbuhler JR, Allwork SP, Anderson RH.The spectrum of Ebstein's anomaly of the tricuspid valve. J Thorac Cardiovasc Surg 1979; 77:202-211

17. Chauvaud S, Mihaileanu S, Gaer J, Carpentier A. Surgical treatment of Ebstein's malformation. The 'Ho'pital Broussais' experience. Cardiol Young 1996; 6:4-11

18. Celermajer DS, Cullen S, Sullivan ID, et al. Outcome in neonates with Ebstein's anomaly. J Am Coll Cardiol 1992; 19:1041-6

19. Pavlova M, Fouron J, Drblik SP, et al. Factors affecting the prognosis of Ebstein's anomaly during fetal life. Am Heart J 1998; 135:1081-5

20. Till J, Celermajer D, Deanfield J. The natural history of arrhythmias in Ebstein's anomaly. J Am Coll Cardiol 1992; 19:273A. 273A

21. Watson H. Natural history of Ebstein's anomaly of tricuspid valve in childhood and adolescence. An international cooperative study of 505 cases. Br Heart J 1974;36:417-27

22. Stellin G, Santini F, Thiene G, et al. Pulmonary atresia, intact ventricular septum, and Ebstein anomaly of the tricuspid valve. J Thorac Cardiovasc Surg 1993; 106:255-61

23. Hong YM, Moller JH. Ebstein's anomaly: a long-term study of survival. Am Heart J 1993;125:1419-24

24. Celermajer DS, Bull C, Till JA, et al. Ebstein's anomaly presentation and outcome from fetus to adult. J Am Coll Cardiol 1994; 23:170- 6

25. Kiziltan HT, Theodoro DA, Wames CA, et al. Late results of bioprosthetic tricuspid valve replacement in Ebstein's anomaly. Ann Thorac Surg 1998;66:1539- 45

26. Quaegebeur JM, Sreeram N, Fraser AG, et al. Surgery for Ebstein's anomaly: the clinical and echocardiographic evaluation of a new technique. J Am Coll Cardiol 991; 17: 722- 8

27. Gentles TL, Calder AL, Clarkson PM, Neutze JM.Predictors of long-term survival with Ebstein's anomaly of the tricuspid valve. Am J Cardiol 1992;69:377- 81

28. Yetman AT, Freedom RM, McCrindle BW.Outcome in cyanotic neonates with Ebstein's anomaly. Am J Cardiol 1998; 81:749-54

29. Roberson DA, Silverman NH. Ebstein's anomaly: echocardiographic and clinical features in the fetus and neonate. J Am Coll Cardiol 1989; 14:1300-7 
30. Suzuki H, Nakasato M, Sato S, Komatsu H, Hayasaka K. Management of functional pulmonary atresia with isoproterenol in a neonate with Ebstein's anomaly. Tohoku J Exp Med 1997; 181:459-65

31. Kapustal L, Eveleighl RM, Poulino SE, Rijlaarsdam ME, du Marchie SGJ, Strengers JL, Delhaas T, de Korte CL, Feuth T, Helbing WA. Ebstein's anomaly: factors associated with death in childhood and adolescence: a multi-centre,long-term study European Heart Joumal.2007; September 24

32. Christopher J. Knott-Craig, Edward D. Overholt, Kent E. Ward and Jerry D. Razook. Neonatal repair of Ebstein's anomaly: indications, surgical technique, and medium-term follow-up. Ann Thorac Surg 2000; 69:1505-1510 33. Chauvaud S, Fuzellier JF, Berrebi A, Lajos P, Marino JP, Mihaileanu $\mathrm{S}$, et al. Bi-directional cavopulmonary shunt associated with ventriculo and valvuloplasty in Ebstein's anomaly: benefits in high risk patients. Eur J Cardiothorac Surg 1998; 13:514-519 